\title{
(1) (Apes: (Anesthesiology \\ LOCAL ANAESTESIA FOR AWAKE FIBEROPTIC INTUBATION: A COMPARISON OF TWO TECHNIQUES- AIRWAY NERVE BLOCKS VS 'SPRAY AS YOU GO' TECHNIQUE
}

\section{Dr. Priyanka Mankar* Dr. (Col) Girish Saundattikar}

Post Graduate Resident, Department of Anesthesiology and Critical Care, Smt Kashibai Navale Medical College, Pune *Corresponding Author

Ex Professor and Head,Department of Anesthesiology and Critical Care, Smt Kashibai Navale Medical College, Pune

ABSTRACT Background- Awake fiberoptic intubation is the recommended technique for anticipated difficult airway management which requires effective local anesthesia for patient's comfort and co-operation. In this study, we compared airway nerve blocks and "Spray as you go" technique for awake fiberoptic intubation in difficult airway patients. Method- Sixty adult patients with an anticipated difficult airway with Mallampati Class III and IV were selected and randomized into two groups for awake fiberoptic intubation. Each group receiving lignocaine as a local anesthetic with either of two different methods. Group $\mathrm{A}(\mathrm{n}=30)$ via airway nerve blocks using transtracheal and superior laryngeal nerve block; and group $\mathrm{B}(\mathrm{n}=30)$ via intubating fiberscope using 'spray as you go' technique. We compared two groups using the Number of attempts for intubation, Intubation time, Intubating conditions, Cough count, Hemodynamic response, Severity scale [patients comfort], and the additional required dose of lignocaine used. Descriptive statistics were done for all data. $p$-value $<0.05$ was considered statistically significant.The result- we found that airway nerve blocks provide better local anesthesia by providing good intubating conditions with less cough count, less intubation time, and better hemodynamic stability as compare to spray as you go group. None of the patients showed any evidence of lignocaine toxicity. But an additional dose of lignocaine used was significantly more number of patients in the spray as you go, group. However patient comfort and acceptance is equal in both groups as patient severity score was the same in both groups and all patients got successfully intubated in both the groups Conclusion- airway nerve block technique of local anesthesia is better than spray as you go method however spray as you go technique can be used in cases where airway blocks are not possible.

\section{KEYWORDS : Awake fiberoptic intubation, airway nerve blocks, "Spray as you go" technique, Difficult airway}

\section{INTRODUCTION}

A prerequisite for awake fiberoptic intubation is appropriate anesthesia of the nose, oropharynx, larynx, and trachea, to suppress airway reflexes and prevent discomfort during bronchoscopy and intubation(Kohli et al., 2014). Prior to bronchoscopy, the upper airway is commonly anesthetized by local lignocaine spray or gel, viscous solutions, soaked cotton pledgets, and nebulization. The modalities of applying a local anesthetic to the larynx and lower respiratory tract include injection via the fiberoptic bronchoscope and transtracheal injection delivery via a nebulizer(Webb et al., 1990)

Despite the availability of these numerous methods for airway anesthesia, few studies have compared them. Inevitably the patient's tolerance and the success of fiberoptic-assisted intubation depend on the effectiveness of topical anesthesia and obtundation of pharyngeal, laryngeal, and tracheobronchial reflexes (Prudon et al., 2005). The better local anesthetic technique would require a lower dose of local anesthetic. It would be safe and not unpleasant for the patient and would at the same time provide acceptable conditions for the bronchoscopist.(Mathur et al., 2018)

Hence, this study aims to compare local anesthetic application techniques, i.e., airway nerve blocks and "Spray as you go" technique for patients undergoing awake fiberoptic intubation.

\section{METHODOLOGY}

This study was conducted after receiving approval from the ethical committee of our institution. In this Prospective, randomized comparative study, sixty adult patients of American Society of Anaesthesiologists (ASA) status I-II between the age group of 18 to 60 years were included. All the patients had an anticipated difficult airway with Mallampati Class III and IV and underwent awake fiberoptic intubation for an elective surgery requiring general anesthesia. Patients were randomized into two groups using a computer-generated random table number. Each group received lignocaine as a local anesthetic with either of two different methods. Group A $(n=30)$ via airway nerve blocks using transtracheal and superior laryngeal nerve block; and group $\mathrm{B}(\mathrm{n}=30)$ via intubating fiberscope using 'spray as you go' technique.

Anesthesia Procedure: Procedure of anesthesia was explained to the patient and written informed consent taken. All the patients included in the study overnight fasted. In the preoperative room intravenous access was established and injection glycopyrrolate $4 \mathrm{mcg} / \mathrm{kg}$ given 30 mins before, nebulization given with $4 \mathrm{ml}$ of $4 \%$ of lignocaine in both groups. In the operation theater, monitoring instituted, viz, electrocardiogram (ECG), oxygen saturation, and noninvasive blood pressure (NIBP). Premedication in the form of intravenous injection ondansetron $0.1 \mathrm{mg} / \mathrm{kg}$, injection midazolam $0.02-0.05 \mathrm{mg} / \mathrm{kg}$, and injection fentanyl 2 microgram $/ \mathrm{kg}$ was given. Further 2 drops of $0.1 \%$ xylometazoline were instilled in each nostril. Thereafter nasal passage was lubricated with $2 \mathrm{ml}$ of $2 \%$ lignocaine jelly.

Then laryngotracheal anesthesia before bronchoscopy done as fallowing

An additional dose of lignocaine as required was given in both the group.

Fiberoptic bronchoscopy was done by the same trained anesthesiologist to avoid subjective errors in results. After confirming nasal patency, dilatation of the desired nostril done with the lubricated soft nasopharyngeal airway. Fiberoptic bronchoscope inserted through the same nostril. The lubricated portex endotracheal tube of appropriate size was passed through nares after the visualization of carinal bifurcation. The endotracheal tube slid off the fiberoptic bronchoscope and mild tracheal placement was confirmed under direct vision. After confirmation of endotracheal intubation by capnography, general anesthesia was achieved with propofol $(2 \mathrm{mg} / \mathrm{kg}$, IV) and vecuronium bromide $(0.1 \mathrm{mg} / \mathrm{kg}$, IV). The patient's vitals were monitored throughout the procedure. Number of attempts for intubation, Intubation time, Intubating conditions, Cough count, Hemodynamic response were noted during the procedure, and Severity scale[ patients comfort] was assessed in the postoperative room when patient fully recovered from anesthesia.

Figure 1: Methodology illustrated

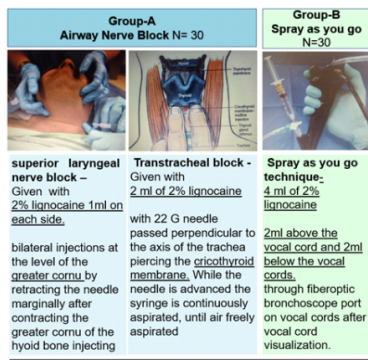


Volume - 10 | Issue - 9 | September - 2020 | PRINT ISSN No. 2249 - 555X | DOI : 10.36106/ijar

RESULTANDANALYSIS

TABLE 1: Demographic characteristics

\begin{tabular}{|c|c|c|c|c|}
\hline \multicolumn{2}{|c|}{ Characteristic } & Group: A & Group: B & Significance \\
\hline \multicolumn{2}{|c|}{ Age } & $39.57 \pm$ & $41.97 \pm$ & $\mathrm{p}=0.442$ \\
\hline \multirow[t]{2}{*}{ Gender } & Males & 16 & 14 & \multirow[t]{2}{*}{$\mathrm{p}=0.606$} \\
\hline & Females & 14 & 16 & \\
\hline \multicolumn{2}{|c|}{ Weight } & $\begin{array}{c}60.07 \pm \\
7.296\end{array}$ & $\begin{array}{c}59.43 \pm \\
6.252\end{array}$ & $\mathrm{p}=0.830$ \\
\hline
\end{tabular}

Both groups were well matched.

TABLE 2: Comparison of baseline characteristics between the two groups

\begin{tabular}{|c|c|c|c|}
\hline Characteristic & Group: A & Group: B & Significance \\
\hline Baseline pulse & $78.40 \pm 12.489$ & $79.20 \pm$ & $\mathrm{p}=0.778$ \\
(beats/min) & & 12.502 & \\
\hline Baseline mean & $81.23 \pm 10.500$ & $80.33 \pm$ & $\mathrm{p}=0.673$ \\
arterial pressure & & 10.509 & \\
(in mm of Hg) & & & \\
\hline
\end{tabular}

Further hemodynamic monitoring was done at the following stages of the procedure

Stage 1 at the insertion of the bronchoscope

Stage 2 at the time of intubation

Then after every 5 minutes till 20 minutes.

TABLE 3: Comparison of the pulse between the two groups*

\begin{tabular}{|c|c|c|c|}
\hline Pulse & Group: A & Group: B & Significance \\
\hline st e 1 & $65.87 \pm 7.829$ & $\begin{array}{c}73.37 \pm \\
11.903\end{array}$ & $\mathrm{p}=0.28$ \\
\hline stage 2 & $72.10 \pm 9.301$ & $\begin{array}{c}94.77 \pm \\
14.097\end{array}$ & $\mathrm{p}=<0.001$ \\
\hline 5 minutes & $74.03 \pm 8.105$ & $\begin{array}{c}94.33 \pm \\
11.040\end{array}$ & $\mathrm{p}=<0.001$ \\
\hline 10 minutes & $73.93 \pm 7.056$ & $\begin{array}{c}93.13 \pm \\
9.573\end{array}$ & $\mathrm{p}=<0.001$ \\
\hline 15 minutes & $72.30 \pm 6.618$ & $\begin{array}{c}91.27 \pm \\
9.146\end{array}$ & $\mathrm{p}=<0.001$ \\
\hline 20 minutes & $71.60 \pm 6.568$ & $\begin{array}{c}89.60 \pm \\
8.431 \\
\end{array}$ & $\mathrm{p}=<0.001$ \\
\hline \multicolumn{4}{|c|}{ *Mann-Whitney U test was used } \\
\hline
\end{tabular}

There was an increase in pulse rate in both groups at stage 1but the difference was not statistically significant. Group B showed a higher increase in pulse rate as compared to group A at stage 2, thereafter at 5 mins, 10 mins, 15 mins, 20 mins. Increase in pulse rate was statistically significant in group B with p-value $<0.001$

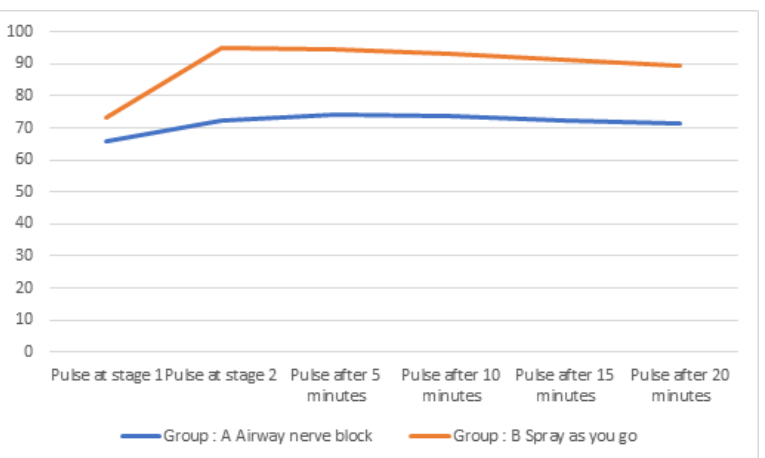

FIGURE 2 : Comparison of Pulse rate in two groups

TABLE4: Comparison of mean arterial pressure (MAP) between the two groups *

\begin{tabular}{|c|c|c|c|}
\hline MAP & Group: $\mathbf{A}$ & Group: $\mathbf{B}$ & Significance \\
\hline stage 1 & $88.80 \pm 10.807$ & $91.47 \pm 11.156$ & $\mathrm{p}=0.236$ \\
\hline stage 2 & $91.30 \pm 10.768$ & $93.37 \pm 11.217$ & $\mathrm{p}=0.355$ \\
\hline 5 minutes & $91.43 \pm 9.583$ & $93.37 \pm 10.440$ & $\mathrm{p}=0.339$ \\
\hline 10 minutes & $87.77 \pm 9.047$ & $91.40 \pm 8.812$ & $\mathrm{p}=0.109$ \\
\hline 15 minutes & $84.23 \pm 7.454$ & $89.10 \pm 8.864$ & $\mathrm{P}=0.014$ (significant) \\
\hline 20 minutes & $81.10 \pm 7.685$ & $86.47 \pm 8.537$ & $\mathrm{P}=0.009$ (significant) \\
\hline *Mann-Whitney U test was used. \\
\hline
\end{tabular}

There was an increase in mean arterial pressure in both the groups but it was not statistically significant at stage 1 , stage $2,5 \mathrm{mins}$, and $10 \mathrm{mins}$. There was a significant increase in mean arterial pressure at $15 \mathrm{mins}$ and 20 mins in group B.

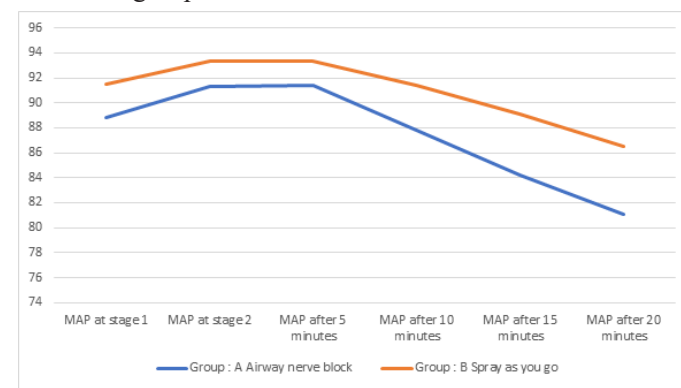

FIGURE 3: Comparison of MAP in two groups

TABLE 5: Comparison means of lowest SpO2 noted in two groups*

\begin{tabular}{|c|c|c|c|}
\hline $\begin{array}{c}\text { Lowest SpO2 } \\
\text { noted }\end{array}$ & Group: A & Group: B & Significance \\
\hline Mean & $96.93 \%$ & $97.13 \%$ & $\mathrm{p}=0.393$ \\
\hline \multicolumn{4}{|c|}{ *Mann-Whitney U test was used. } \\
\hline
\end{tabular}

Patients in both groups exhibited a slight decrease in SpO2 during the procedure, but it was not statistically significant.

TABLE 6: Comparison of the number of attempts of intubation in two groups*

\begin{tabular}{|c|c|c|c|}
\hline $\begin{array}{c}\text { Attempts of } \\
\text { intubation }\end{array}$ & Group: A & Group: B & Significance \\
\hline 1 & 28 & 28 & \multirow{2}{*}{$\mathrm{p}=1.000$} \\
\hline 2 & 2 & 2 & \\
\hline \multicolumn{3}{|c|}{$*$ Chi-square test. } \\
\hline
\end{tabular}

All patients got intubated in a single attempt, except for two patients in each group required two attempts for intubation.

TABLE 7: Comparison of mean time taken for intubation in two groups*

\begin{tabular}{|c|c|c|c|}
\hline $\begin{array}{c}\text { Time is taken for } \\
\text { intubation (in } \\
\text { seconds) }\end{array}$ & Group: A & Group: B & Significance \\
\hline & $200.37 \pm$ & $230.73 \pm$ & $\mathrm{p}=$ \\
& 39.853 & 38.259 & 0.002 (significant) \\
\hline & $*$ Mann-Whitney U test was used for comparison \\
& \multicolumn{3}{|c|}{ between two groups } \\
\hline
\end{tabular}

The time is taken to perform FOB guided intubation was less in Group $\mathrm{A}(200.37 \pm 39.853)$ as + compared with Group B (230.73 \pm 38.259$)$ and this was statistically significant.

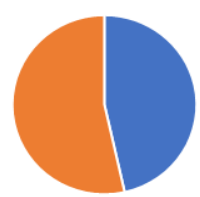

- Group : A Airway nerve block - Group : B Sprat as you go

FIGURE 4. Comparison of time taken for intubation in two group

TABLE 8: Comparison of intubating conditions in two groups*

\begin{tabular}{|l|l|l|l|}
\hline $\begin{array}{l}\text { Intubating } \\
\text { conditions }\end{array}$ & Group: A & Group: B & Significance \\
\hline I & 10 & 2 & $\mathrm{p}=0.002$ \\
II & 16 & 16 & \\
\hline III & 2 & 10 & \\
\cline { 1 - 3 } IV & 2 & 2 & \\
\cline { 1 - 2 } *Chi-square test used. & \multicolumn{2}{|l}{} \\
\hline
\end{tabular}

Grading of overall intubating conditions (as assessed by the endoscopist)

I - No adverse events, cough or stridor, co-operative and well-tolerated II - Coughed once or twice, co-operative with reassurance, tolerated 
the tube well.

III - Coughed repeatedly, no stridor, tube accepted

IV- Coughed repeatedly, stridor present, unco-operative, did not allow a scope to be passed beyond glottis

All patients got intubated successfully, intubating conditions were graded by anesthesiologist performing bronchoscopy were significantly better in group $\mathrm{A}(\mathrm{p}<0.002)$

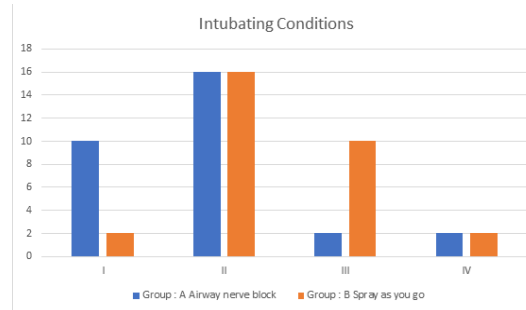

FIGURE 5. Comparison of intubating conditions in two groups

TABLE 9: Comparison of severity of intubation in two groups*

\begin{tabular}{|c|c|c|c|}
\hline $\begin{array}{c}\text { Patient Severity } \\
\text { index }\end{array}$ & Group: A & Group: B & Significance \\
\hline 1 & 20 & 19 & \multirow{2}{*}{$\begin{array}{c}\text { p }=0.893 \\
\text { (Not significant) }\end{array}$} \\
\hline 2 & 8 & 8 & \\
\hline 3 & 2 & 3 & \\
\hline 4 & 0 & 0 & \\
\hline \multicolumn{3}{|c|}{${ }^{*}$ Chi-square test used. } \\
\hline
\end{tabular}

Here,

1 -Not unpleasant

2 -Uncomfortable

3 -Unpleasant

4 -Most unpleasant

5 -Intolerable

Both techniques of local anesthesia were equally tolerated by patients in both groups.

TABLE 10: Comparison of cough count in two groups*

\begin{tabular}{|c|c|c|c|}
\hline Cough count & Group: A & Group: B & Significance \\
\hline 1 & 3 & 0 & \multirow{2}{p}{$\begin{array}{c}\text { p }=<0.001 \\
\text { (significant) }\end{array}$} \\
\hline 2 & 23 & 3 & \\
\hline 3 & 3 & 13 & \\
\hline 4 & 1 & 14 & \\
\hline \multicolumn{2}{|c|}{${ }^{*}$ Chi-square test used for comparison between two groups. } \\
\hline
\end{tabular}

The cough counts during the procedure were recorded as the mean count per procedure. The total number of coughs was significantly less in group A compared with group $\mathrm{B}(\mathrm{p}<0.001)$.

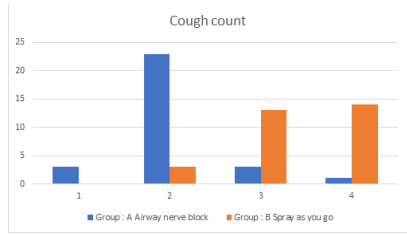

FIGURE 6. Comparison of cough count in two groups

TABLE 11- Number of patients required an additional dose of lignocaine

\begin{tabular}{|c|c|c|c|}
\hline $\begin{array}{c}\text { An additional dose } \\
\text { of Lignocaine } \\
\text { required }\end{array}$ & Group: A & Group: B & Significance \\
\hline No & 28 & 11 & $\begin{array}{c}\mathrm{p}=<0.001 \\
\text { (significant) }\end{array}$ \\
\hline Yes & 2 & 19 & \\
\hline \multicolumn{3}{|c|}{ *Chi-square test used. } \\
\hline
\end{tabular}

None of the patients showed any evidence of lignocaine toxicity. But an additional dose of lignocaine used was significantly more number of patients in Group B as compared with Group A.

\section{DISCUSSION}

An awake patient is also likely to have some amount of awareness of the passage of the FOB and endotracheal tube despite adequate topical anesthesia and sedation. Passage of the endotracheal tube through the glottic opening provides the maximum stimulus to hemodynamic changes(Of \& Airway., n.d.).

In our study, the heart rate increased gradually and progressively with each stage in the intubation process and was above baseline values with each stage in both the groups, starting with the introduction of FOB (Table no.3). There was an increase in heart rate at stage- 1 that is at the insertion of the fibreoptic bronchoscope in both the groups but an increase in heart rate at this stage was not statistically significant. However, the maximal increase in HR above baseline levels occurred during placement of the endotracheal tube in the trachea that is stage 2 . An increase in heart rate was statistically significant in group B (mean $94.77 \pm 14.097$ beats $/ \mathrm{min}$ ) at stage 2 . At 5 th minute (by which time more than $80 \%$ of patients had a successful passage of ETT), the HR was $74.03 \pm 8.105 \mathrm{bpm}$ in group A and $94.33 \pm 11.040$ in group B. Increase in heart rate at 5 mins was statistically significant in group B. Further heart rate monitoring was done until 20 mins, which showed a statistically significant increase in heart rate in group B than group A.

Blood pressure (MAP) increased gradually with each stage in the intubation process and was above baseline values in both the groups (table no.4). The maximal increase in blood pressure above baseline levels occurred during placement of the endotracheal tube in the trachea (group A- $91.30 \pm 10.768 \mathrm{mmhg}$, group B- $93.37 \pm 11.217$ ). Increase in MAP was persisted till 20 minutes in group B (at 15 mins$89.10 \pm 8.864 \mathrm{mmHg}$, at 20 mins- $86.47 \pm 8.537 \mathrm{mmHg}$ ) which was statistically significant as compared to group A with $\mathrm{p}<0.05$ (Table 4) Hence, we found airway nerve blocks produce less hemodynamic changes ( stress response) during awake fiberoptic intubation than spray as you go.

Lt Col N Sethi et al(Sethi, Tarneja, Madhusudanan, \& Shouche, 2005) found that there was no statistically significant difference between any groups at any interval for $\mathrm{HR}$ or BP.

In our study, most of the patients remained stable (Table no.5). The mean of the lowest $\mathrm{SpO} 2$ noted in group A was $96.93 \%$ and in the group, B was $97.13 \%$. The difference was not statistically significant. However Lowest $\mathrm{SpO} 2$ noted was $92 \%$ in group A and $94 \%$ in group B which were overcome by instilling oxygen through a catheter connected to the working channel of FOB(Apfelbaum et al., 2013), aided by awake and spontaneously breathing patients In our study use of fentanyl may be responsible for this much fall in spo2 due to respiratory depressant action of fentanyl.(Bhattacharya et al., 2015)

All patients were successfully intubated in both groups. The time is taken to perform FOB guided intubation was less in Group A(200.37 \pm $39.853)$ as compared with Group B $(230.73 \pm 38.259)$ and this was statistically significant. (table no 7) which is a reflection of a better quality of local anesthesia and intubating condition afforded. Also, Alka Chandra et al(Chandra A, Banavaliker JN, n.d.) in 2011 found that mean time to reach carina was significantly lesser in transcricoid injection group $(57.33 \pm 12.98 \mathrm{~s})$ as compared to spray as you go group $(79.33 \pm 22.35 \mathrm{~s})$ during fiberoptic bronchoscopy $(\mathrm{p}<0.02)$. Our results are contradictory to study conducted by Lt Col N Sethi et al(Sethi et al., 2005) in which the time is taken (mean) for intubation was significantly less in the spray as you go as compared to Transcricoid injection and nebulization. Reasoner et al,(Reasoner DK, Warner DS, Todd MM, Hunt SW, n.d.) found no significant difference in intubation time between nerve block and topical anesthesia groups. In different studies of nasotracheal fibreoptic intubation under regional anesthesia, the average time taken for intubation is 2 to 3 minutes for successful endotracheal intubation was observed(Kundra, Kutralam, \& Ravishankar, 2000)(Sethi et al., 2005)

In our study, All patients got intubated in a single attempt, except two patients in both groups who developed stridor required $2^{\text {nd }}$ attempt of bronchoscopy for intubation. The difference was not statistically significant. (table no 6). .In a study conducted by Lt Col N Sethi et al(Sethi et al., 2005), there was no significant difference in the number of intubation attempts between the three groups. The use of FOB requires adequate training in Mannikin initially(Coe PA, King TA, n.d.) and actual clinical cases. Due to a lack of familiarity with the equipment and its handling, initial attempts always take time(Johnson C, n.d.). Therefore, in our study Fiberoptic bronchoscopy was done by the same trained anesthesiologist to avoid subjective errors in results All patients got intubated successfully, we found that intubating conditions were graded by anesthesiologists performing 
bronchoscopy were significantly better in group A (table no 8). Only 4 patients in group A had a grading of intubation more than II, whereas 12 patients in group B had intubating grade more than II. Two patients in both groups developed stridor. our result was consistent with Lt Col N Sethi et al(Sethi et al., 2005)

The total number of coughs was significantly less in group A compared with group B (table no.10). Only 4 patients in group A coughed more twice whereas 27 patients in group B coughed more than twice Our findings are contradictory to Lt Col N Sethi et al(Sethi et al., 2005) -a total number of coughs was significantly less in the 'spray as you go' technique This difference can be due to the technique of nerve block used as in our study we gave combined superior laryngeal and transtracheal block whereas Lt Col N Sethi et al used only transtracheal block. Webb et al,(Webb et al., 1990)found transcricoid injection of lignocaine produced less cough than spray-as-you-go technique. However, one-third of patients found the cricothyroid puncture to be unpleasant and better acceptance of the spray-as-you-go- technique. Even though the transcricoid injection often produces a cough, it is short-lived and not associated with the unpleasant sensation of not being able to eject a foreign object. As the primary reason for topical anesthesia of the respiratory mucosa is to reduce cough, the reduced rate of cough (with a lower dosage of a local anesthetic) produced by the transcricoid technique is a clear advantage.(Webb et al., 1990)

Patient cooperation and immobility must always be ensured during FOB and intubation. In our study, the Severity scale (as reported by the patient) shown that the bronchoscopy was not particularly unpleasant for the patients in either group and coughing was the most common reason for any unpleasantness in both groups. Both techniques of local anesthesia were equally tolerated by patients. About 20 patients in group A and 19 patients in group B had patient severity index 1 which is suggestive of that procedure was pleasant. 8 patients in both groups had severity scale 2. (table no.9)Our findings are consistent with the study of Webb et al, neither local anesthetic technique (block or spray) was associated with a more unpleasant bronchoscopy for the patient. Also, in the study conducted by P. Kundra et al(Kundra et al., 2000), the majority of patients $(83 \%)$ had comfortable in the combined regional airway block. However, Lt Col N Sethi et al(Sethi et al., 2005) found that patients' VAS showed a significant preference for the 'spray as you go' technique and also the severity scores showed that fiberoptic and endotracheal intubation in the spray as you go group patients was the least distressing.

None of the patients showed any evidence of lignocaine toxicity. But an additional dose of lignocaine used was significantly more number of patients in Group B as compared with Group A . $(n=19$ in Group B as compared to $\mathrm{n}=2$ in Group A). 19 patients in group B i.e spray as you go required extra dose of lignocaine for the successful passage of bronchoscope through the trachea. Only 2 patients in group A i.e airway nerve block required additional lignocaine during $2^{\text {nd }}$ attempt of intubation in the form of spray as you go technique. So we found, airway nerve block provided better intubating conditions with less cough and less dose of local anesthetic. Our findings are consistent with the study of Lt Col N Sethi et al- Although group B (spray as you go) patients had the least amount of coughing and choking the amount of extra lignocaine used ( $60 \mathrm{mg}$ mean) was more than group A i.e transtracheal injection $(20 \mathrm{mg}$ mean) but less than group $\mathrm{C}$ i.e nebulization (120 mg mean). Although none of the patients displayed any adverse effects.

\section{CONCLUSION}

We conclude that airway nerve block technique of local anesthesia is better than spray as you go method by providing good intubating conditions with less cough count, less intubation time, better hemodynamic stability and requires less dose of lignocaine however spray as you go technique can be used in cases where airway blocks are not possible.

\section{REFERENCES}

1. Apfelbaum, J. L., Hagberg, C. A., Caplan, R. A., Blitt, C. D., Connis, R. T., Nickinovich, D. G., ... Ovassapian, A. (2013). Practice Guidelines for Management of the Difficult D. G., ... Ovassapian, A. (2013). Practice Guidelines for Management of the Difficult
Airway. Anesthesiology, 118(2), 251-270. https:// doi. org/ 10.1097/ ALN. 0b0 13e Airway. Anest

2. Bhattacharya, S., Choudhury, B., Mallick, S., Prasad, A., Mondal, S., \& Ghosh, S. (2015). Comparison between dexmedetomidine and fentanyl on intubation conditions during awake fiberoptic bronchoscopy: A randomized double-blind prospective study. Journal of Anaesthesiology Clinical Pharmacology, 31(2), 212. https://doi.org/ $10.4103 / 0970-9185.155151$

3. Chandra A, Banavaliker JN, A. M. (n.d.). Fibreoptic bronchoscopy without sedation: Is transcricoid injection better than the"spray as you go" technique?. Indian J Anaesth

\section{1;55:483-7.}

4. Coe PA, King TA, T. R. (n.d.). Teaching guided fibreoptic nasotracheal intubation. An assessment of an anaesthetic technique to aid training. Anaesthesia 1988; 43:410-413.

5. Johnson C, R. J. (n.d.). Clinical competence in the performance of fiberoptic laryngoscopy and endotracheal intubation: A study of resident instruction. J Clin Anesth 1989; 1:344-349.

6. Kohli, S., Farooque, K., Jalwal, G., Gupta, D., Sinha, S., Chandralekha, \& Gupta, B. (2014). Topical airway anesthesia for awake fiberoptic intubation: Comparison between (2014). Topical airway anesthesia for awake fiberoptic intubation: Comparison between
airway nerve blocks and nebulized lignocaine by ultrasonic nebulizer. Saudi Journal of airway nerve blocks and nebulized lignocaine by ultrasonic nebuliz
Anaesthesia, 8(5), 15. https://doi.org/10.4103/1658-354X.144056

7. Kundra, P., Kutralam, S., \& Ravishankar, M. (2000). Local anaesthesia for awake fibreoptic nasotracheal intubation. Acta Anaesthesiologica Scandinavica, 44(5), 511-516. https://doi.org/10.1034/j.1399-6576.2000.00503.x

8. Mathur, P. R., Jain, N., Kumar, A., Thada, B., Mathur, V., \& Garg, D. (2018) Comparison between lignocaine nebulization and airway nerve block for awake fiberoptic bronchoscopy-guided nasotracheal intubation: a single-blind randomized proce prospective study. Kor Joun

9. Of, A. S. of A. T. F. on M., \& Airway., the D. (n.d.). Practice guidelines for management of the difficult airway Anesthesiology 2003; 98:1269-1277.

10. Prudon, B., Birring, S. S., Vara, D. D., Hall, A. P., Thompson, J. P., \& Pavord, I. D (2005). Cough and Glottic-Stop Reflex Sensitivity in Health and Disease. Chest, 127(2), 550-557. https://doi.org/10.1378/chest.127.2.550

11. Reasoner DK, Warner DS, Todd MM, Hunt SW, K. J. (n.d.). A comparison of anesthetic techniques for awake intubation in neurosurgical patients. J Neurosurg Anesthesio 1995; 7: 94-9.

12. Sethi, N., Tarneja, V. K., Madhusudanan, T. P., \& Shouche, S. (2005). Local anaesthesia for fiberoptic intubation: A comparison of three techniques. Medical Journal Armed Forces India, 61(1), 22-25. https://doi.org/10.1016/S0377-1237(05)80112-1

13. Webb, A. R., Fernando, S. S. D., Dalton, H. R., Arrowsmith, J. E., Woodhead, M. A., \& Cummin, A. R. C. (1990). Local anaesthesia for fibreoptic bronchoscopy: Transcricoid injection or the "spray as you go" technique? Thorax, 45(6), 474-477. https://doi. org $10.1136 /$ thx.45.6.474 